\title{
Multicriteria Decision Analysis Applied to an Electrical Power System: Case Study
}

Xavier Aguas, María Campoverde, Vanessa Benavides, Nataly Pozo, Marcelo Pozo Departamento de Automatización y Control Electrónico Industrial Escuela Politécnica Nacional Quito, Ecuador xavier.aguas@epn.edu.ec

\section{ABSTRACT}

Commonly, the interaction of power systems is to provide energy depending on the demand. The introduction of renewable energy to the electrical system brings a new challenge to the transmission system operator. This new challenge is related to the decision criteria due to the variability of the source that not necessarily match with the demand. Thus, the goal of this paper is to present a multicriteria decision analysis in order to set which power source could be used depending on the season. For this study, the decision deck software "diviz" is used. The results show that for dry and rainy season, hydropower is the best option.

Keywords: Decision making, multicriteria analysis, multicriteria, tradeoffs, electrical power system. 


\section{Introduction}

In the last twenty years, the integration of renewable energy to the electrical system is now a reality. The total installed capacity considering marine, solar, wind and hydropower is closed to $2 \mathrm{GW}$ [1]. The integration of these renewable energy affects to voltage and frequency stability [2]. This is because the demand does not match with the intermittent behavior of the source [3].

Therefore, the main challenge for transmission system operators is to adapt their decision not only to prices but also to availability of the source. For this decision some multicriteria decision making framework to rank renewable energy projects has been presented by several studies [4], [5]. For instance, Harambopoulos and Polatidis suggests a multi criteria method that includes: fuel saved, return on investment, environmental and risk index, and number of jobs created [6].

Different methods have been studied in order to rank renewable energy in the electrical system. Some of the multi criteria decision method are: PROMETHEE, ELECTRE, VIKOR, TOPSIS. The advantages and disadvantages of each method has been presented by [7]. Depending on the multicriteria decision method and weighting technique, the results can vary. The application of any method of multicriteria analysis assumes the need to determine which objectives of the decision maker intends to achieve. Other method that has not been deeply applied on renewable energy is the additive weighting method (AWM).

Thus, the present work evaluates an example of an electrical power system with different types of energy sources (hydroelectric, thermoelectric, renewables and non-conventional) considering the AWM. In the study, transmission lines, power compensators, and loads are also considered. The goal is to choose the best option of power source obtained by a hierarchical order. This procedure was performed manually and the results were validated with the software DIVIZ. The paper is structured as follow: the explanation of the multicriteria decision analysis is developed in Section 2. Then, the additive weighting method is explained and applied in section 3. Section 4 presents the results of the study developed. Finally, some conclusions are drawn. 
Background on multicriteria decision making

The main strength of the multicriteria methods is their ability to rotate around questions characterized by contradictory assessments, allowing a comprehensive evaluation of the problem in question [8]. Multicriteria decision problems consist of a problem where there are at least two alternatives to choose, this choice is developed by the desire to comply several objectives that often conflict with each other. The objectives are variables that are associated with the evaluation and authorization of each alternative to fulfil a specific purpose. These variables can be called criteria, attributes or dimensions.

A decision model is a formal representation and simplification of the problem that has support of a multicriteria method to make decisions. These models help to describe and analyse the problem of interest. Through a multicriteria method, decisions are made to achieve the previously established objectives.

The basic elements for multicriteria decision are explained as follow:

- Alternatives $\left(\mathbf{a}_{\mathbf{n}}\right)$ : The concept of alternative corresponds to the particular case in which modelling is such that two distinct potential actions can in no way be conjointly put into operation.

- Criteria $\left(\mathbf{c}_{\mathbf{n}}\right)$ : A criterion is a tool constructed for evaluating and comparing alternatives according to a particular point of view. This evaluation must take into account, for each action, all the pertinent effects or attributes linked to the point of view considered.

- Consequences: It is the combination of the alternatives and criteria, forming a matrix with each element that represents the relationship between each of the alternatives and the criteria.

- Problematic: It presents a vision in the quality or result intended in a certain problem, can be identified in four types of problematic:

- Choice problem $(\alpha)$ : Clarify the decision to choose a subset of the value space.

- Classification problem $(\beta)$ : Assign to each action a class.

- Management problem $(\gamma)$ : Sort actions.

- Description problem : Support the decision through a description of the actions and their consequences.

The procedure used to order the scale constants of each of the criteria will be the trade-off procedure. According to [9], the trade-off procedure has six steps:

1. Intra criterion evaluation: It consists in evaluating each alternative i for each criterion $j$, obtaining a value function for each alternative $\left(v_{i}\left(a_{i}\right)\right)$. This function allows to construct an array of consequences that represents the problem to be solved.

2. Criteria ordering: If pairs of consequences are compared in order to sort the criteria according to the consequence they represent. This comparison is made considering that consequence 1 will have the maximum value for criterion $\mathrm{i}$ and the minimum value for the other criteria; However, consequence 2 will have the maximum value for criterion $j$ 
and the minimum value for the other criteria; Where $i \neq j$.

3. Obtaining the relation between the scale constants: If comparisons are made based on the step of ordering criteria. The maximum value of the criterion of the preferred consequence is decreased and the values are maintained in the non-preferred consequence until an indifference relation is obtained.

4. Make all the necessary comparisons in order to achieve the values of weights.

5. Exploring the space of consequences: If you try to find more comparisons for the decision maker you will improve your assessment.

6. Consistency tests are performed on the results.

Several methods have been applied for multicriteria decision. In this paper, the additive method is the chosen for the present study. This helps to sort the options in a hierarchical structure, where numerical values are obtained that represent the priority of each alternative. The use of this method makes it possible to identify the criteria used for decision making, also provides a hierarchical structure, assigns weights to each criterion to establish its importance, thus synthesizing all information for better decision.

To carry out this method, it is necessary to find the value function $\left(v_{j}\left(a_{i}\right)\right)$ for each criterion $j$. The general formulation of the problem is as follow:

$$
v(a)=\sum_{1}^{n} k_{i} v_{j}(a)
$$

Where $k_{i}$ represents a weight for criterion $j$.

$$
\sum_{j=1}^{n} k_{j}
$$

For the determination of the weights for each criterion, the trade-off method is used. This method emphasizes the degree of importance of each criterion. The method establishes the degree of interaction between all variables. The systems are normalized, i.e. the scale is between 0 to 1 , and the variables are ordered by importance, which are obtained by the additive method, i.e. the sum of all the criteria must be 1 :

$$
\begin{aligned}
& c_{1}=0.5 c_{7} \\
& c_{3}=0.9 c_{1} \\
& c_{2}=0.7 c_{3} \\
& c_{4}=0.9 c_{2}
\end{aligned}
$$




\section{Case study}

Fort the proposed methodology, a case study is proposed. In this case, the alternatives considered takes into account the type of power generation. These alternatives are:

- Hydroelectric power station.

- Thermal Power Plant.

- Non-Conventional Plants.

- Interconnection (losses, loads)

Additionally, the multicriteria for the decision making in an electrical power system is described as follow:

- The generation of a structure at peak hour for a day of maximum power demand in the rainy season $\left(c_{1}\right)$ : In a rainy period, hour of maximum demand is determined in as the time, respectively hour of the peak of demand. An analysis of the contributing of the energy sources is carried out, and as result of this analysis the percentage of contribution of each type of energy source is obtained.

- The structure of generation in a day of maximum demand, in rainy period $\left(\mathrm{c}_{2}\right)$ : In a rainy period, the day of maximum demand is determined as the time in which the peak of demand exists. An analysis of the contributing energies is carried out and the result is the percentage of contribution of each type of energy source.

- The generation structure at peak hour for the day of maximum power demand of the dry season $\left(c_{3}\right)$ : In a dry period, the hour of maximum demand is determined as the time in which the peak of demand exists. An analysis of the contributing energy types is carried out and the percentage of contribution of each type of energy is obtained.

- The structure of generation throughout the day of maximum demand, dry period $\left(\mathrm{c}_{4}\right)$ : In a dry period, the day of maximum demand is determined, an analysis of the contributing energies is carried out and the result is the percentage of contribution of each type of energy.

- Generation structure in the hour of minimum demand of the year $\left(\mathrm{c}_{5}\right)$ :The percentage of the energy provided by different types of energy generation is shown, for the hour of minimum demand.

- Structure of generation throughout the day of minimum demand of the year $\left(\mathrm{c}_{6}\right)$ : The percentage of energy supplied by different types of energy generation is shown, by day of minimum demand.

- Total net energy production $\left(c_{7}\right)$ : It is the energy provided by the different types of energy generation, in GWh, in one year. 
Taking into consideration these criterions and the weight factor, the order of each criterion is organized in table 1. Additionally, the normalized matrix where the relation of the alternatives and the criterions assumed are in table 2. In this case, more importance is given to hydropower and thermal station instead of non-conventional power plants.

\section{$3 \quad$ Case study}

Fort the proposed methodology, a case study is proposed. In this case, the alternatives considered takes into account the type of power generation. These alternatives are:

- Hydroelectric power station.

- Thermal Power Plant.

- Non-Conventional Plants.

- Interconnection (losses, loads)

Additionally, the multicriteria for the decision making in an electrical power system is described as follow:

- The generation of a structure at peak hour for a day of maximum power demand in the rainy season $\left(c_{1}\right)$ : In a rainy period, hour of maximum demand is determined in as the time, respectively hour of the peak of demand. An analysis of the contributing of the energy sources is carried out, and as result of this analysis the percentage of contribution of each type of energy source is obtained.

- The structure of generation in a day of maximum demand, in rainy period $\left(\mathrm{c}_{2}\right)$ : In a rainy period, the day of maximum demand is determined as the time in which the peak of demand exists. An analysis of the contributing energies is carried out and the result is the percentage of contribution of each type of energy source.

- The generation structure at peak hour for the day of maximum power demand of the dry season $\left(c_{3}\right)$ : In a dry period, the hour of maximum demand is determined as the time in which the peak of demand exists. An analysis of the contributing energy types is carried out and the percentage of contribution of each type of energy is obtained.

- The structure of generation throughout the day of maximum demand, dry period $\left(\mathrm{c}_{4}\right)$ : In a dry period, the day of maximum demand is determined, an analysis of the contributing energies is carried out and the result is the percentage of contribution of each type of energy.

- Generation structure in the hour of minimum demand of the year $\left(\mathrm{c}_{5}\right)$ :The percentage of the energy provided by different types of energy generation is shown, for the hour of minimum demand.

- Structure of generation throughout the day of minimum demand of the year $\left(\mathrm{c}_{6}\right)$ : The percentage of energy supplied by different types of energy generation is shown, by day of minimum demand.

- Total net energy production $\left(c_{7}\right)$ : It is the energy provided by the different types of energy generation, in GWh, in one year. 
Taking into consideration these criterions and the weight factor, the order of each criterion is organized in table 1. Additionally, the normalized matrix where the relation of the alternatives and the criterions assumed are in table 2. In this case, more importance is given to hydropower and thermal station instead of non-conventional power plants.

\section{TABLE VI \\ WEIGHTS OF CRITERIA}

\begin{tabular}{ccc}
\hline \hline Order & Criteria & Weights \\
\hline 1 & C7 & 0.3847 \\
2 & C1 & 0.1923 \\
3 & C3 & 0.1731 \\
4 & C2 & 0.1212 \\
5 & C4 & 0.1091 \\
6 & C5 & 0.0109 \\
7 & C6 & 0.0087 \\
\hline \hline
\end{tabular}

Table II

STANDARIZATION MATRIX

\begin{tabular}{cccccccc}
\hline \hline Alternatives & $\mathrm{C} 1$ & $\mathrm{C} 2$ & $\mathrm{C} 3$ & $\mathrm{C} 4$ & $\mathrm{C} 5$ & $\mathrm{C} 6$ & $\mathrm{C} 7$ \\
\hline $\begin{array}{c}\text { Hydroelectric } \\
\text { Power Station. }\end{array}$ & 0.5956 & 0.6688 & 0.5583 & 0.4672 & 0.4185 & 0.4899 & 0.5495 \\
$\begin{array}{c}\text { Thermoelectric } \\
\text { power station. }\end{array}$ & 0.3618 & 0.3182 & 0.4020 & 0.4880 & 0.5511 & 0.4333 & 0.3861 \\
$\begin{array}{c}\text { Non-Conventional } \\
\quad \text { Plants. }\end{array}$ & 0.0383 & 0.0073 & 0.0187 & 0.0188 & 0.0190 & 0.0501 & 0.0224 \\
$\begin{array}{c}\text { Interconnection. } \\
\text { Plercion }\end{array}$ & 0.0043 & 0.0057 & 0.021 & 0.0258 & 0.0114 & 0.0267 & 0.0419 \\
\hline \hline
\end{tabular}




\section{$4 \quad$ Results of the proposed method}

To begin the analysis, a study of each of the criteria and how affect the proposed alternatives is developed using the software "diviz". The analysis is developed by means of the star graph method, which shows an objective point of view, as shown in the figures $1-4$.
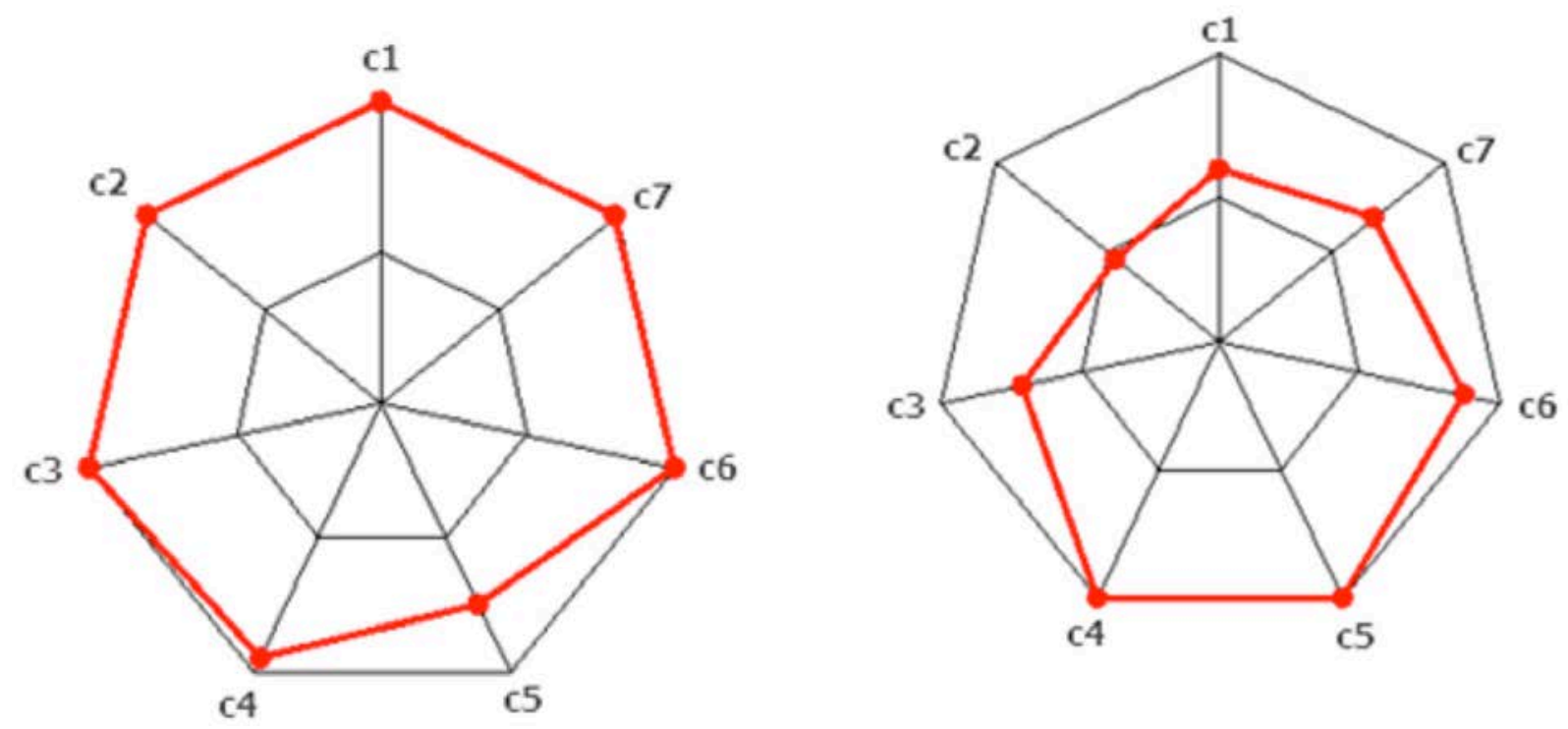

Figure 1. Polar representation of the Hydroelectric alternative. Figure 2. Polar representation of the Thermoelectric alternative.

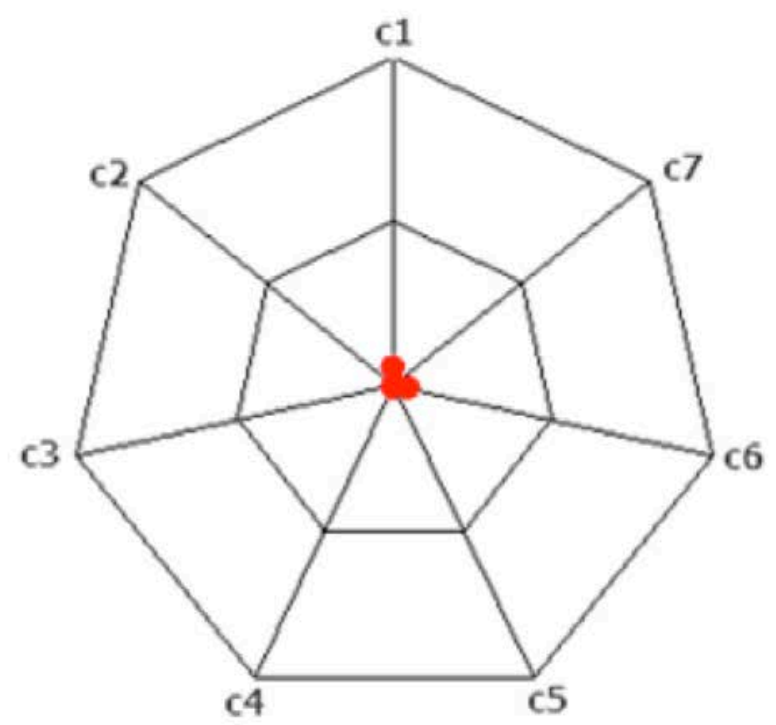

Figure 3. Polar representation of the Interconnection alternative.

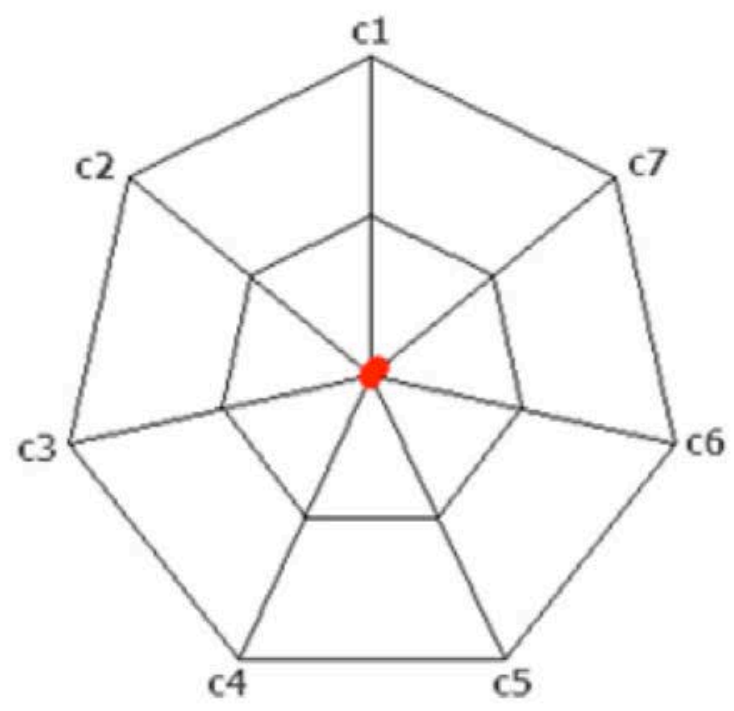

Figure 4. Polar representation of the Nonconventional Central alternative. 
Each of the alternatives has been analysed according to the criteria of priority, the weights are estimated as it is shown Figure 5

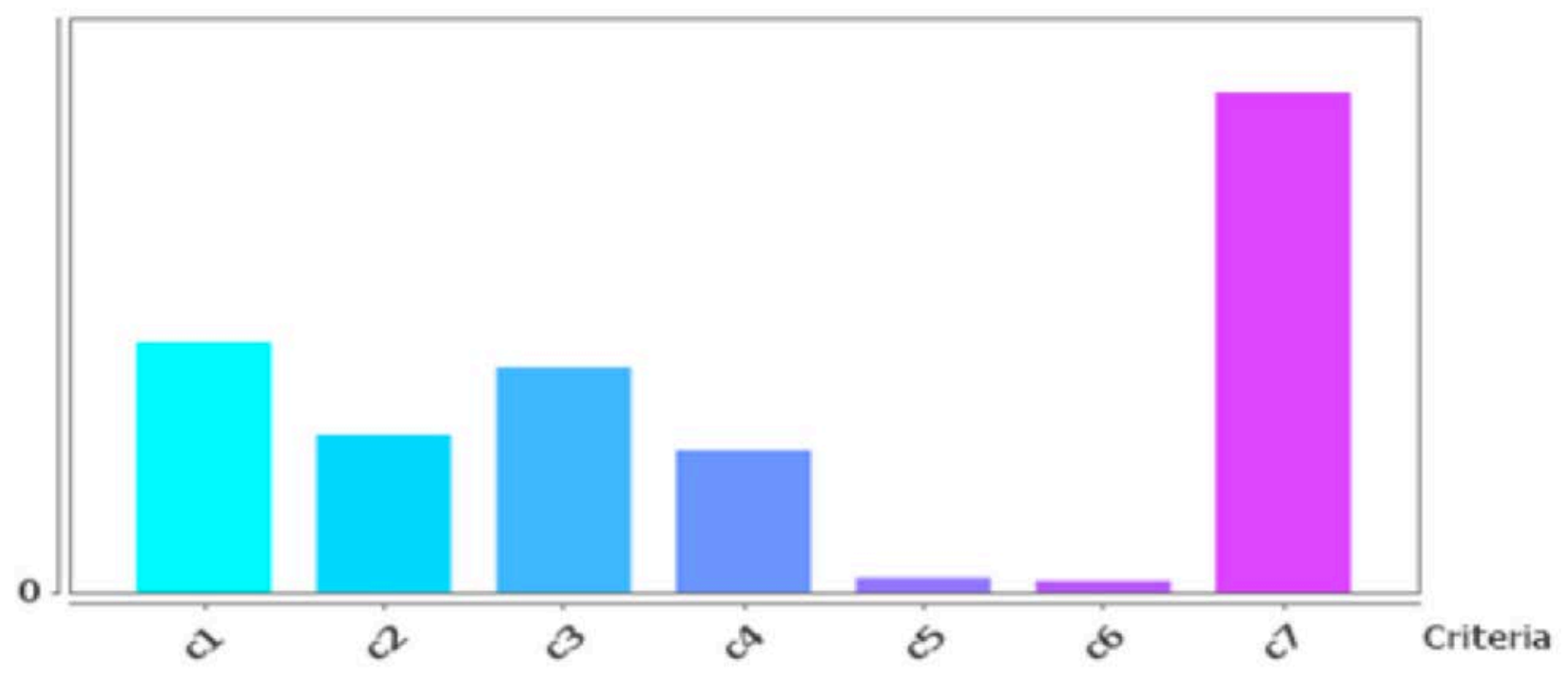

Figure 5. Bar Chart of Weights

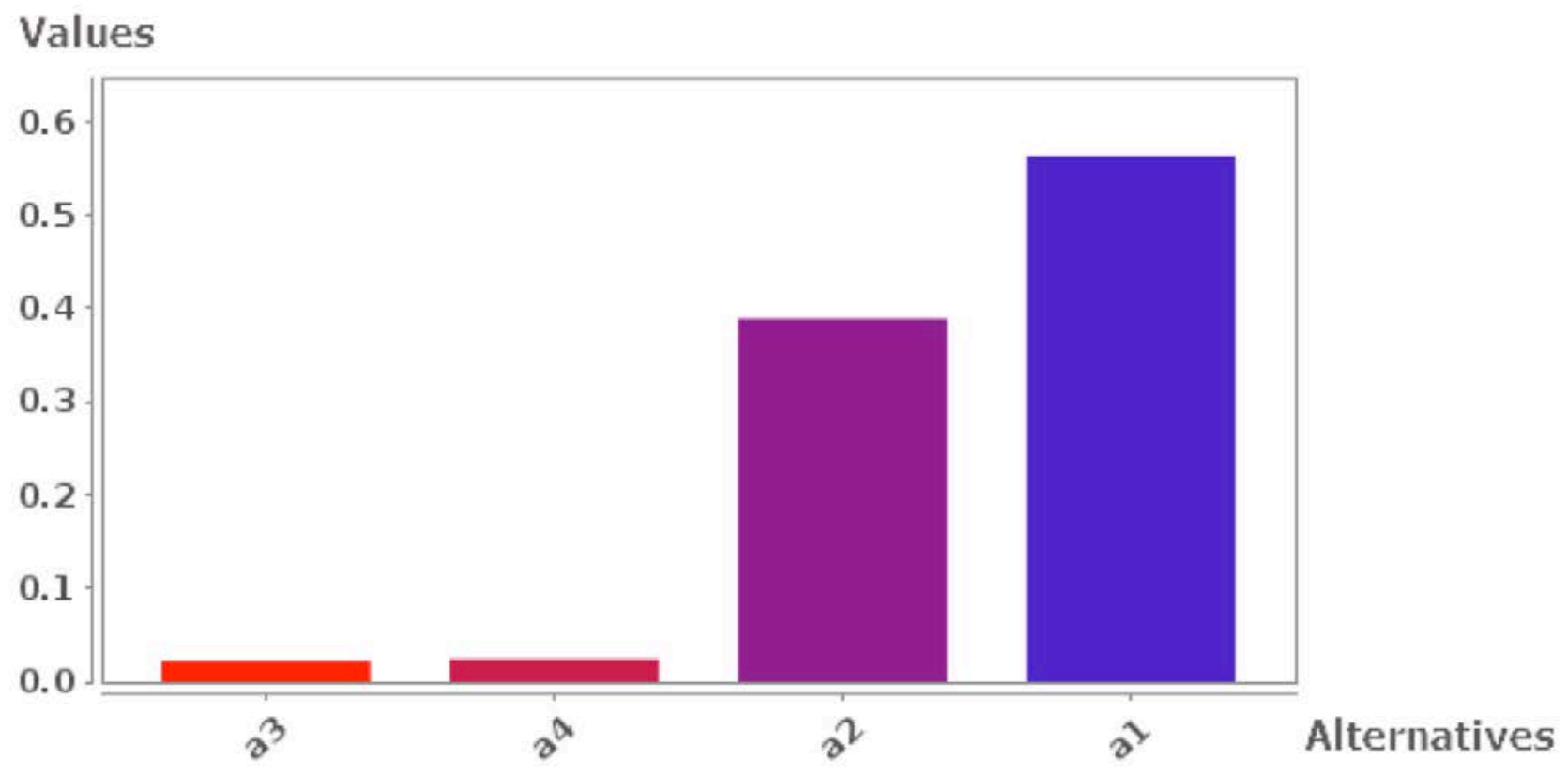

Figure 6. Sequential map showing what is the best alternative to be chosen. 
According to the criteria and the weight, the best solution is alternative 1 . This is that hydroelectric power station is the best used technology. This is because all the different criteria match with this solution. For instance, this technology offers the maximum power supply for the current demand for rainy season or dry season. However, the worst-case scenario is the non-conventional power plants due to the variability of the resource that affects in any time: dry or rainy season.

\section{$5 \quad$ Conclusions}

This paper has presented a multicriteria analysis for decision making method in order to find the best alternative. The study case is focused on a general grid that considers hydropower, thermal power plant, non-conventional generation and interconnection with other power systems. The different criteria were explained and studied. Then, the solution was modelled in "diviz" software.

The results show that the hydropower has the highest weight factors. This is because, it is considered that it has a larger contribution than the other alternatives. After using the trade-off method, the present method determined the hierarchical order of the alternatives. In this case, the first alternative is the hydropower and the last one is the interconnection together with the non-conventional.

\section{$6 \quad$ References}

[1.] "IRENA Resource." [Online]. Available: http://resourceirena.irena.org. [Accessed: 19Feb-2015].

[2.] A. Cabrera-Tobar and O. Gomis-Bellmunt, "Dynamic study of a photovoltaic power plant interconnected with the grid," in IEEE PES Innovative Smart Grid Technologies Conference Europe, 2017.

[3.] T. H. Al-Theanat and M. A. Lpizra, "The Effects of Intermittent Solar Radiation in Off-grid Solar Power System A Case Study of Two Cities; Irbid and Abu Dhabi 'Worst Month' Method," Int. J. Eng. Innov. Res., vol. 4, no. 4, pp. 2277-5668.

[4.] B. Ozorhon, A. Batmaz, and S. Caglayan, "Generating a framework to facilitate decision making in renewable energy investments," Renew. Sustain. Energy Rev., vol. 95, pp. 217-226, Nov. 2018.

[5.] N. H. Afgan and M. G. Carvalho, "Multi-criteria assessment of new and renewable energy power plants," Energy, vol. 27, no. 8, pp. 739-755, Aug. 2002.

[6.] D. A. Haralambopoulos and H. Polatidis, "Renewable energy projects: structuring a multi-criteria group decision-making framework," Renew. Energy, vol. 28, no. 6, pp. 961-973, May 2003.

[7.] H.-C. Lee and C.-T. Chang, "Comparative analysis of MCDM methods for ranking renewable energy sources in Taiwan," Renew. Sustain. Energy Rev., vol. 92, pp. 883896, Sep. 2018.

[8.] L. Abdullah and C. W. R. Adawiyah, "Simple Additive Weighting Methods of Multi criteria Decision Making and Applications: A Decade Review." 2014. 
[9.]A. T. de Almeida, J. A. de Almeida, A. P. C. S. Costa, and A. T. de Almeida-Filho, "A new method for elicitation of criteria weights in additive models: Flexible and interactive tradeoff," Eur. J. Oper. Res., vol. 250, no. 1, pp. 179-191, Apr. 2016. 


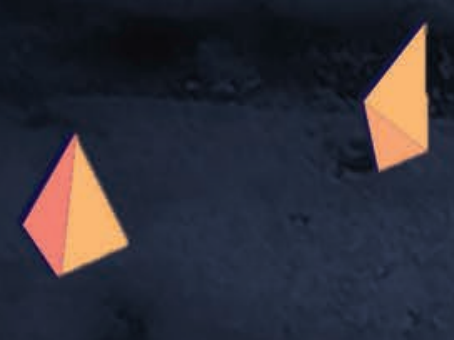

$1(1)$

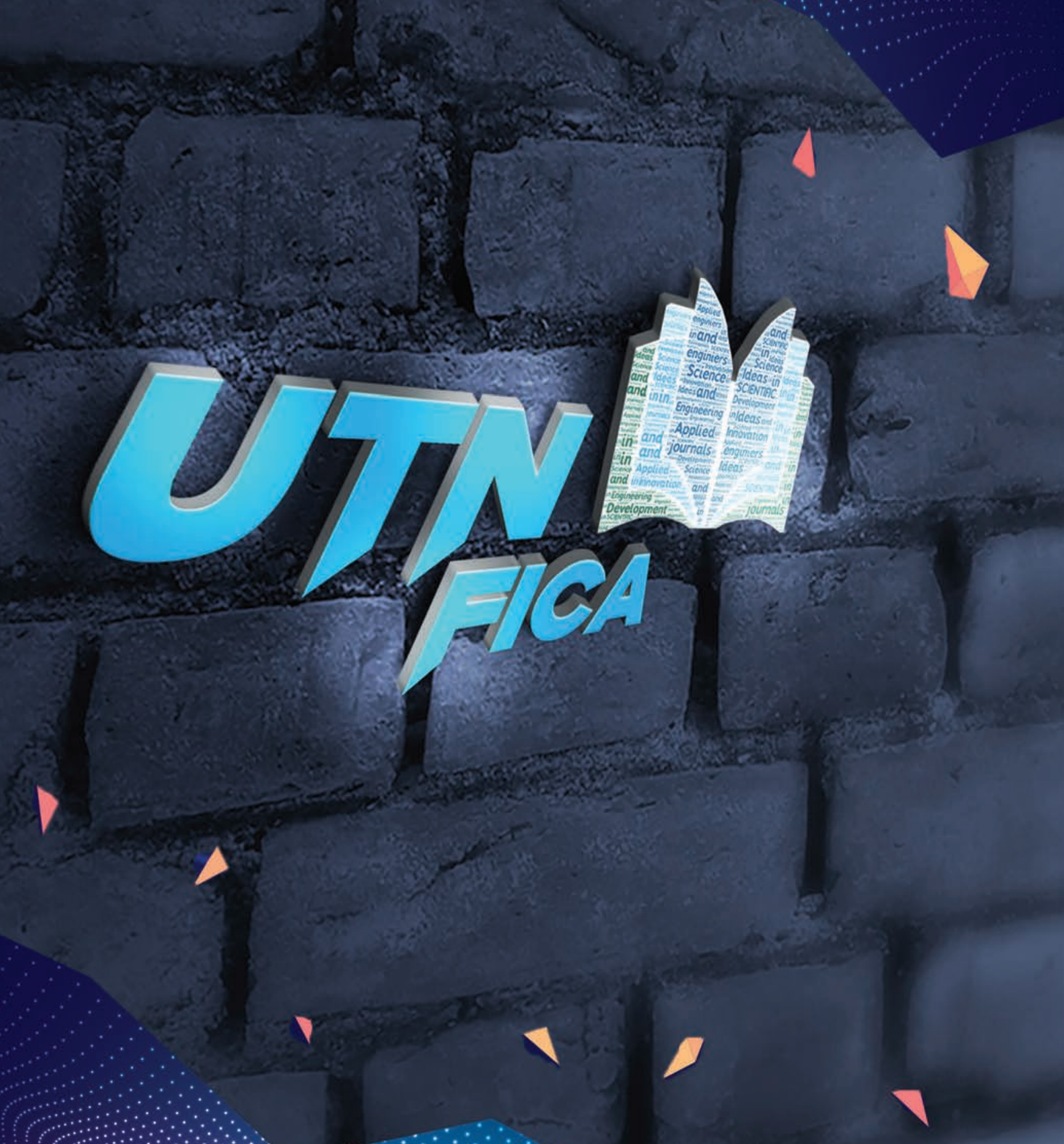

की (C) (C) 